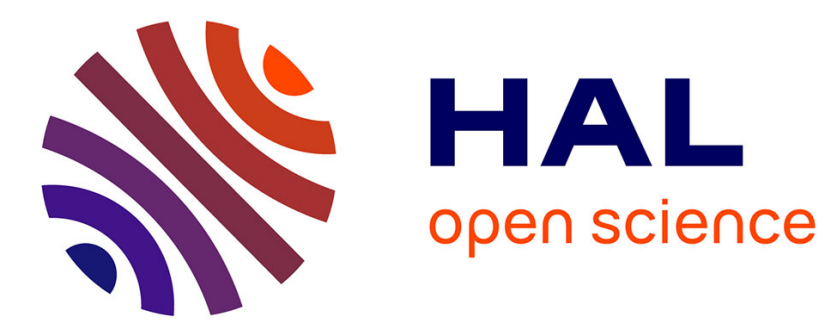

\title{
Understanding the material flow path of friction stir welding process using unthreaded tools
}

\author{
Olivier Lorrain, Véronique Favier, Didier Lawrjaniec, Hamid Zahrouni
}

\section{To cite this version:}

Olivier Lorrain, Véronique Favier, Didier Lawrjaniec, Hamid Zahrouni. Understanding the material flow path of friction stir welding process using unthreaded tools. Journal of Materials Processing Technology, 2010, 210 (4), pp.603-609. 10.1016/j.jmatprotec.2009.11.005 . hal-02456305

\section{HAL Id: hal-02456305 https://hal.science/hal-02456305}

Submitted on 27 Jan 2020

HAL is a multi-disciplinary open access archive for the deposit and dissemination of scientific research documents, whether they are published or not. The documents may come from teaching and research institutions in France or abroad, or from public or private research centers.
L'archive ouverte pluridisciplinaire HAL, est destinée au dépôt et à la diffusion de documents scientifiques de niveau recherche, publiés ou non, émanant des établissements d'enseignement et de recherche français ou étrangers, des laboratoires publics ou privés. 


\title{
Understanding the material flow path of friction stir welding process using unthreaded tools
}

\author{
Olivier Lorrain ${ }^{\mathrm{a}, *}$, Véronique Favier ${ }^{\mathrm{b}},{\text { Hamid } \text { Zahrouni }^{\mathrm{c}} \text {, Didier Lawrjaniec }}^{\mathrm{d}}$ \\ a Arts et Métiers ParisTech-Metz, CNRS, LPMM, 4 rue Augustin Fresnel, 57078 Metz Cedex 3, France \\ b Arts et Métiers ParisTech-Paris, CNRS, LIM, 151, boulevard de l'Hôpital, 75013 Paris, France \\ ' Université de Metz, CNRS, LPMM, Ile du Saulcy, 57045 Metz, France \\ d Plateforme Mécanique et Corrosion, Institut de Soudure Recherche et Enseignement, Espace Cormontaigne, 4, boulevard Henri Becquerel, 57970 Yutz, France
}

Keywords:

Friction stir welding

Material flow

Visualisation

\begin{abstract}
A B S T R A C T
Material flow during friction stir welding is very complex and not fully understood. Most of studies in literature used threaded pins since most industrial applications currently use threaded pins. However, initially threaded tools may become unthreaded because of the tool wear when used for high melting point alloys or reinforced aluminium alloys. In this study, FSW experiments were performed using two different pin profiles. Both pins are unthreaded but have or do not have flat faces. The primary goal is to analyse the flow when unthreaded pins are used to weld thin plates. Cross-sections and longitudinal sections of welds were observed with and without the use of material marker (MM) to investigate the material flow. Material flow with unthreaded pin was found to have the same features as material flow using classical threaded pins: material is deposited in the advancing side (AS) in the upper part of the weld and in the retreating side (RS) in the lower part of the weld; a rotating layer appears around the tool. However, the analysis revealed a too low vertical motion towards the bottom of the weld, attributed to the lack of threads. The product of the plunge force and the rotational speed was found to affect the size of the shoulder dominated zone. This effect is reduced using the cylindrical tapered pin with flats.
\end{abstract}

\section{Introduction}

The friction stir welding (FSW) is a recent process which has been developed by The Welding Institute (TWI) in the beginning of the 1990s. The principle of the process is quite simple: a rotating tool is plunged into the weld joint and is forced to travel down the joint line. The tool is made of two parts: a shoulder which primary heats the plate by friction and a pin which primary stirs the material to avoid hole and to make compact joint. Note that the plastic deformation contributes to heat the material. Zhang and Zhang (2009a) estimated from numerical simulations that the ratio of plastic/frictional dissipation was 0.29 . The process is thus a combination of extruding, forging and stirring of the material. The side where the angular velocity vector and translation velocity vectors are in the same direction is called the advancing side (AS). The side where they are in opposite direction is called the retreating side (RS). The specificity of the process is that the joining of the material is achieved without melting and that hard-to-weld metals have been joined thanks to it.

\footnotetext{
* Corresponding author. Tel. +33 3873755 42; fax: +33 387375431 .

E-mail address: olivier.lorrain@metz.ensam.fr (O. Lorrain).
}

The strength of the joint depends on the degree of mixing of the two weld pieces. How does material flow from front to back around the pin remains the subject of various investigations since material flow around the tool is responsible for the completeness of the mixing (Guerra et al., 2003; Liechty and Webb, 2007; Mishra and Ma, 2005). Some authors offer some interesting results using different marker techniques for aluminium friction stir welding. At the beginning, Colligan (1999) used steel shots positioned at different locations in the sheets to trace the path of the particles during FSW. An aluminium foil of different grade than the base material was used by Reynolds and his co-workers (Reynolds et al., 1999; Seydel and Reynolds, 2001) while copper foil was used by Dickerson et al. (2003), Guerra et al. (2003), Schmidt et al. (2006) and Xu and Deng (2008). Sanders (2007) and Schneider et al. (2006) used tungsten wire to highlight the out of plane movement of the particles. Dissimilar weld have been also performed using two different aluminium grade plates by Li et al. (1999) and Guerra et al. (2003) or plasticine by Gratecap (2007) and Liechty and Webb (2007). All these experiments were made using threaded tools and show similar results concerning the material flow. First of all, in the region near the shoulder, the material is mostly deposited at the AS while deeper in the weld, the material is deposited at the RS. Then, vertical flow of the particles can be observed and is said to form a vortex movement in the nugget zone by Guerra et al. (2003). Tool marks 
(a)
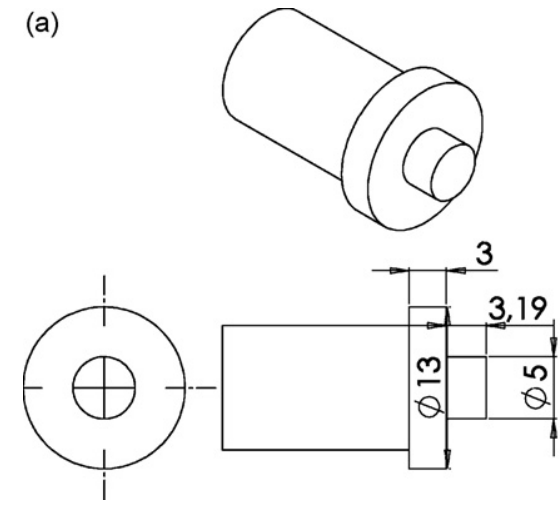

(b)

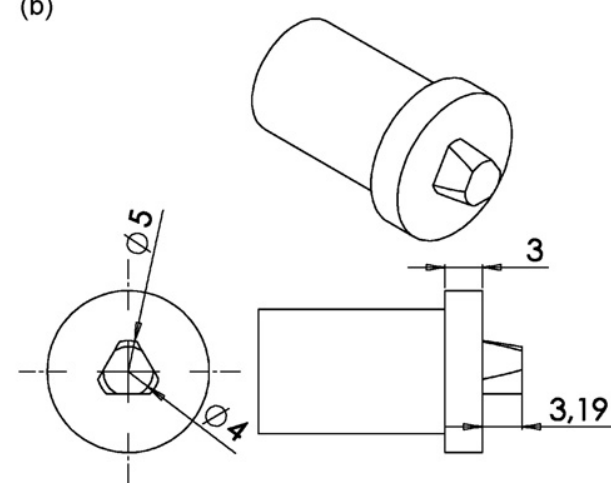

Fig. 1. FSW tool pin profiles: (a) SC tool and (b) TC3F tool. The dimensions are given in mm.

spacing equal to advance by turn were observed by most of the authors as well as distributions by layers of the material in the case of heterogeneous welds. A decomposition of weld in three distinct zones has been proposed by Schmidt et al. (2006). This decomposition suggests reasons why the path is different for particles from AS and the ones from RS.

The present study aims at checking if the results observed using threaded pins can be transferred to FSW experiments using smooth pins. Few studies in literature (Elangovan and Balasubramanian, 2007; Fratini et al., 2006; Prado et al., 2001; Zhao et al., 2005) were interested in material flow using unthreaded tools. Analysing material flow using unthreaded tools is of great interest for two main reasons. First, experiments using smooth tools can be directly used for the validation of a numerical model in which threads are difficult to represent. The interest of such numerical models to simulate FSW processing is clear and has been demonstrated by many literature works. Numerical simulations have been widely used to obtain temperature and mechanical fields (Schmidt and Hattel, 2005; Zhang and Zhang, 2008; Bastier et al., 2008; Fourment and Guerdoux, 2008). They provide a better understanding of the flow and heating mechanisms of FSW depending on the tool profiles, rotation speed, velocity speed, axial force (Colegrove and Shercliff, 2006; Zhang and Zhang, 2009b) in order to optimize the FSW process. Second, initially threaded tool becomes rapidly unthreaded when used for high melting point alloys such as steels and for reinforced aluminium alloys because of the strong tool wear (Prado et al., 2001, 2003). In this work, welds were made using two different tool profiles and copper foils as material marker (MM). Experimental observations are presented for different copper foil orientations and aluminium sheet cuts. The experimental procedure is firstly detailed and then the results are illustrated and discussed. We show the keyrole of the product of the plunge force and the rotational speed on the size of the shoulder dominated zone. Material flow with unthreaded tool was found to have the same features as material flow using classical threaded tools: material is deposited in the advancing side (AS) in the upper part of the weld and in the retreating side (RS) in the lower part of the weld; a rotating layer appears around the pin. However, the analysis revealed a too low vertical motion towards the bottom of the weld, attributed to the lack of threads.

\section{Experimental procedure}

The welds were performed using an ESAB friction stir welding dedicated machine at Institut de Soudure (France) near Metz. The workpiece material was $4 \mathrm{~mm}$ thick aluminium alloy 7020-T6 rolled plates. Two tools, made of high carbon steel, were used to produce the joints. The tool dimensions and geometry are shown in Fig. 1. The tools differ from their pin profile: the first tool has a straight cylindrical pin (SC) whereas the second tool has a tapered cylindrical pin (TC3F) with three flats. The two tools have unthreaded pin. Their shoulder was concave (the concavity is not represented in Fig. 1) and they were tilted by $2.5^{\circ}$ to provide compressive force to the stirred weld zone.

The welding parameters used are listed in the three first columns of Table 1 where $V, F$ and $\omega$ are, respectively, the welding speed, the plunge force and the rotational speed. Rotational and feed speeds ranged, respectively, from 300 to $1620 \mathrm{rpm}$ and 100 to $900 \mathrm{~mm} / \mathrm{min}$ (weld pitch $V / \omega$ ranging from approximately $0.17-1$ ). Two different rotational speeds at a fixed feed speed were used to fabricate the joints. Similarly two different feed speeds at a fixed rotational speed were used. The plunge force, $F$, was adjusted in order to produce external defect free weld. Trial experiments were carried out to find out the working limits of welding parameters. Using this experimental procedure, two kinds of experiments were achieved. The first kind of experiments consists in plunging the tool at the center of the joint in one plate (stir-in-plate). For the second type of experiments, a thin sheet of copper, $0.2 \mathrm{~mm}$ thick, was positioned either along the longitudinal seem side or along the transverse seem side of the panels (Fig. 2).

Transverse cross-sections were investigated on the different welds in transverse directions. Observations have also been performed in two sections containing the welding direction and perpendicular to the tool axis. These sections were located at two different positions along with the plate thickness: just under the shoulder, at the weld root. The different observation plans are

Table 1

Characteristic lengths of weld zone (in $\mathrm{mm}$ ) obtained for various values of welding speed $(V)$, plunge force $(F)$ and rotational speed $(\omega)$ and for the two pins SC and TC3F.

\begin{tabular}{|c|c|c|c|c|c|c|c|c|c|c|c|}
\hline \multirow[t]{2}{*}{$V(\mathrm{~mm} / \mathrm{min})$} & \multirow[t]{2}{*}{$F(\mathrm{~kg})$} & \multirow[t]{2}{*}{$\omega(\mathrm{rpm})$} & \multirow[t]{2}{*}{$V / \omega(\mathrm{mm} /$ turn $)$} & \multicolumn{4}{|l|}{ SC } & \multicolumn{4}{|c|}{ TC3F } \\
\hline & & & & $L_{\mathrm{r}}$ & $L_{1}$ & $L_{2}$ & $L_{3}$ & $L_{\mathrm{r}}$ & $L_{1}$ & $L_{2}$ & $L_{3}$ \\
\hline 100 & 750 & 300 & 0.33 & 4.8 & 5.5 & 6.5 & 8.6 & 4.8 & 5.6 & 6.6 & 8.1 \\
\hline 100 & 600 & 600 & 0.17 & 4.8 & 6.5 & 7.5 & 10.4 & 4.8 & 6.3 & 7.2 & 9.4 \\
\hline 500 & 1100 & 600 & 0.83 & 5.0 & 5.6 & 8.1 & 10.8 & 5.0 & 6.1 & 7.4 & 9.5 \\
\hline 500 & 900 & 900 & 0.56 & 5.2 & 5.8 & 7.0 & 9.8 & 5.1 & 5.7 & 6.9 & 8.9 \\
\hline 900 & 1200 & 900 & 1.00 & 5.2 & 6.4 & 7.4 & 9.1 & 5.2 & 5.8 & 7.0 & 9.0 \\
\hline 900 & 750 & 1620 & 0.56 & 4.6 & 6.2 & 6.1 & 6.1 & 4.3 & 5.8 & 6.1 & 6.2 \\
\hline
\end{tabular}




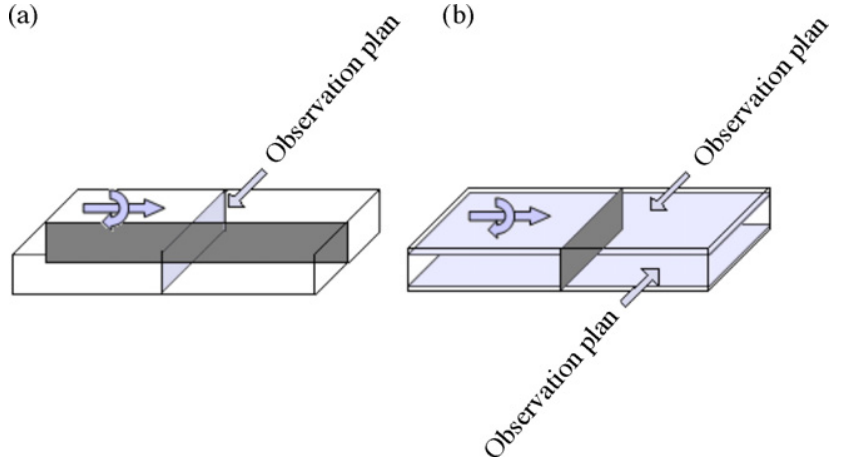

Fig. 2. Schematic representation of the copper foil (dark grey) (a) parallel to the welding direction and (b) perpendicular to the welding direction and respective observation planes (light grey)

illustrated on Fig. 2. The samples were polished using different grade of emery paper. Then, final polishing was done using different diamonds compounds ( 6,3 and $1 \mu \mathrm{m})$. To highlight microstructure, the specimens were etched using classical Keller's reagent (for $100 \mathrm{ml}$ of aqueous solution: $0.5 \mathrm{ml}$ of hydrofluoric acid, $1.5 \mathrm{ml}$ of hydrochloric acid and $2.5 \mathrm{ml}$ of nitric acid). The macrographs presented in the following were made thanks to an optical microscope linked to a computer allowing recording digital imaging. In colored macrograph copper foil is orange and defects are black so they can be distinguished. But in black and white macrographs, as presented here, copper and defects are black.

\section{Results}

The observations presented in this section concern the stir-inplate welds as well as the welds using MM.

\subsection{Analysis of the weld shapes}

Weld macro-sections of joints obtained for the various process parameters summarized in Table 1 were systematically observed.

Firstly, the shape of the weld is analysed. Macro-sections reveal a zone comprising the so-called nugget zone and thermo-mechanical affected zone (TMAZ) which is delimited by dashed lines in Fig. 3. The weld has a vase shape as found commonly in literature (Mishra and Ma, 2005). The larger part is in the upper portion of the weld revealing the key role of the shoulder on the material stirring. The thinner part is in the lower part of the weld. In addition, in the upper portion of the weld, the AS and RS zones are not symmetric. In order to compare more accurately the influence of the process parameters on the weld joint shape, we define four characteristic lengths (Fig. 3):

(1) $L_{\mathrm{r}}$ is the width of the weld in its lower portion (root).

(2) $L_{1}$ is the width of the weld at $1 \mathrm{~mm}$ from the weld root.

(3) $L_{2}$ is the width of the weld at $1 \mathrm{~mm}$ from the weld root.

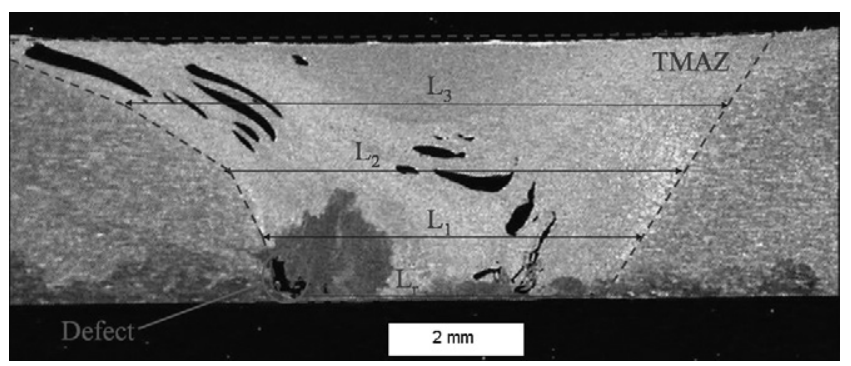

Fig. 3. Typical micrograph of the weld joint and definition of characteristic lengths.
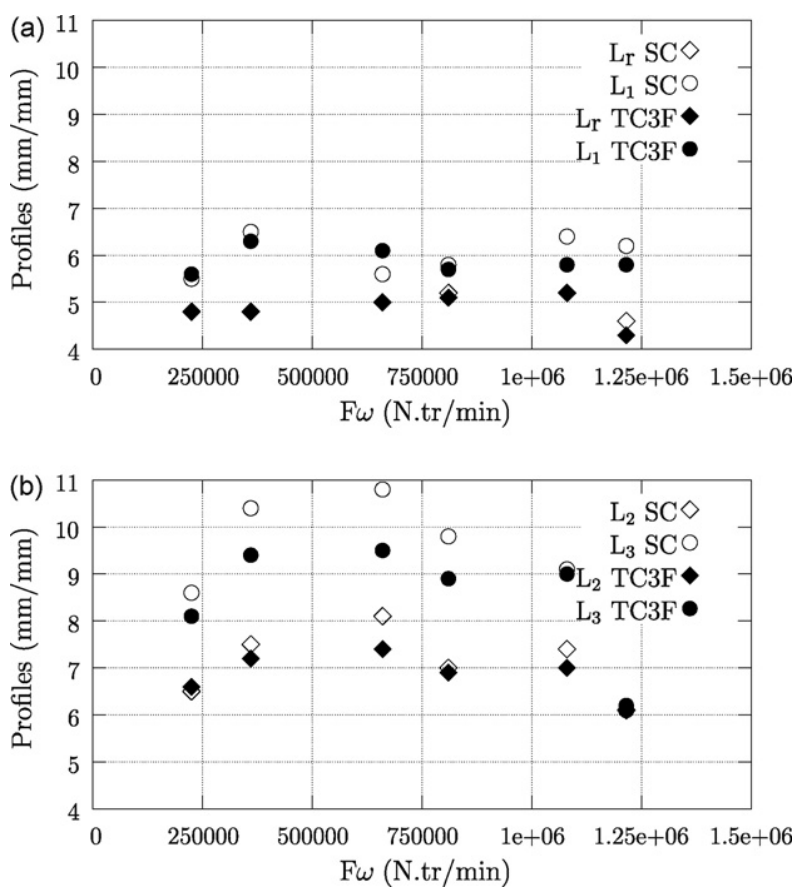

Fig. 4. Influence of $F \omega$ on the characteristics lengths of the weld shape.

(4) $L_{3}$ is the width of the weld at $3 \mathrm{~mm}$ from the weld root.

Table 1 summarizes the results for the different process parameters and tools.

For both pins, $L_{\mathrm{r}}, L_{1}$ and $L_{2}$ do not change significantly with $F$ $V$ or $\omega$. Similarly, $L_{3}$ is not clearly related to $F, V$ or $\omega$ exept when $\omega$ reaches $1620 \mathrm{rpm}$. In this case, $L_{3}$ is more than $30 \%$ lower than for the other cases, irrespective of the pin. However, we found that $L_{2}$ and $L_{3}$ increase and then decrease when increasing the product of the plunge force $F$ and the rotational speed $\omega$ (Fig. 4). As a first approximation, this quantity can be considered as proportional to the heat generated by friction between the shoulder and the workpiece, provided the coefficient of friction remains constant.

In addition, to highlight the shape of the profile, two new quantities have been calculated: global profile GP and local one LP. Global profile (GP), which is equal to $\left(L_{3}-L_{\mathrm{r}}\right) / 3$, gives the "global" slope of the shape. Local profile (LP), which is equal to $\left(L_{3}-L_{2}\right) / 1$ gives the "local" slope. Fig. 5 shows these two profiles versus $F \omega$. The comparison of these two quantities emphasizes the break-up in the shape profile and so characterize the impact of the shoulder on the flow along with the plate thickness. Indeed, a high GP and moreover a high LP mean that the shoulder affects the TMAZ and the nugget not only just underneath the surface but also along with the thickness.

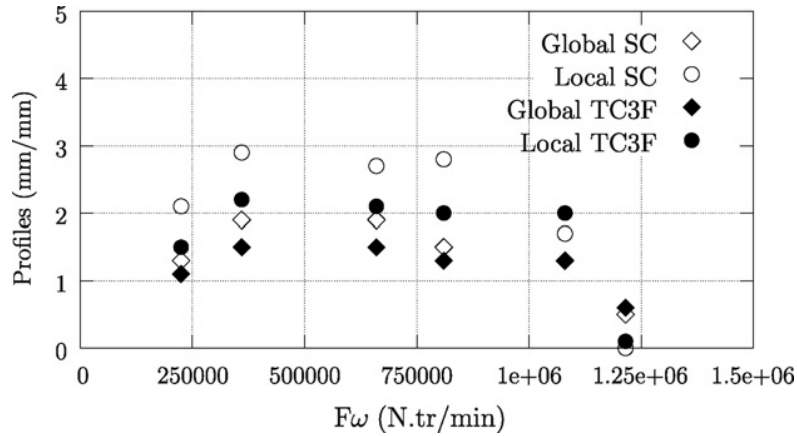

Fig. 5. Influence of $F \omega$ on the global and local profiles of the weld shape. 

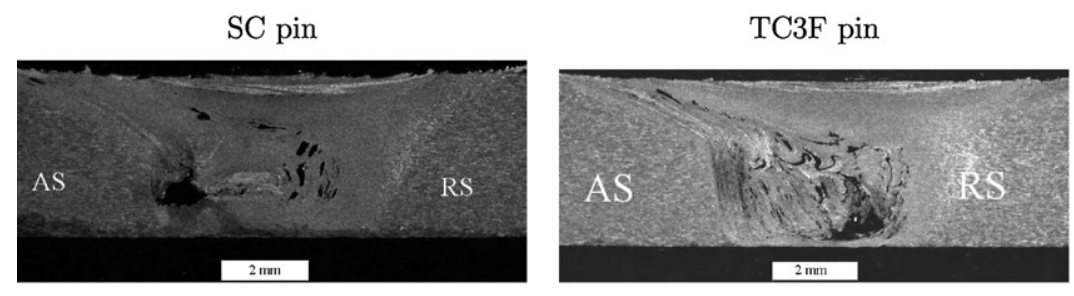

$\mathrm{V}=100 \mathrm{~mm} / \mathrm{min}, \mathrm{F}=750 \mathrm{~kg}, \omega=300 \mathrm{rpm}$
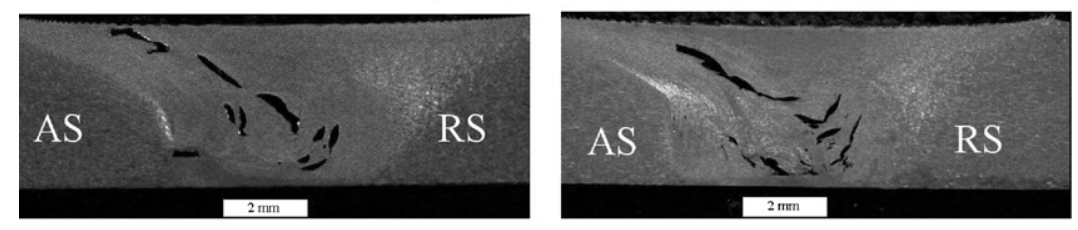

$\mathrm{V}=100 \mathrm{~mm} / \mathrm{min}, \mathrm{F}=600 \mathrm{~kg}, \omega=600 \mathrm{rpm}$
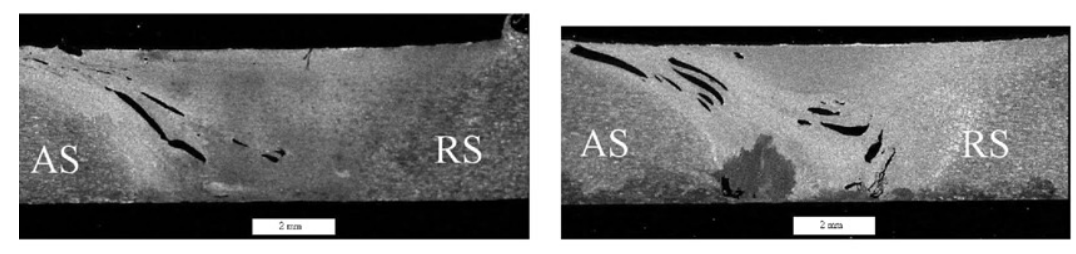

$V=500 \mathrm{~mm} / \mathrm{min}, \mathrm{F}=1100 \mathrm{~kg}, \omega=600 \mathrm{rpm}$
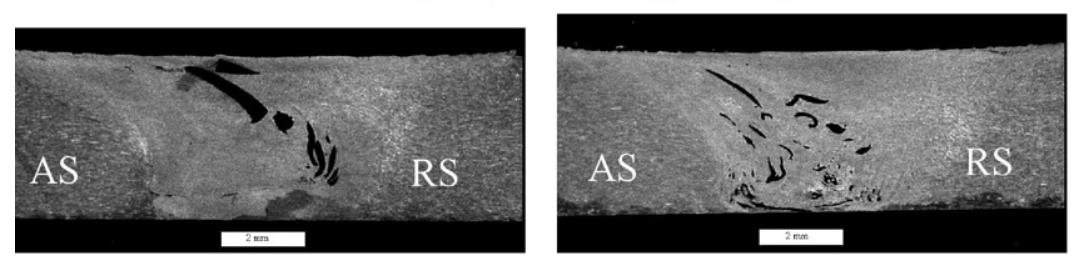

$\mathrm{V}=500 \mathrm{~mm} / \mathrm{min}, \mathrm{F}=900 \mathrm{~kg}, \omega=900 \mathrm{rpm}$
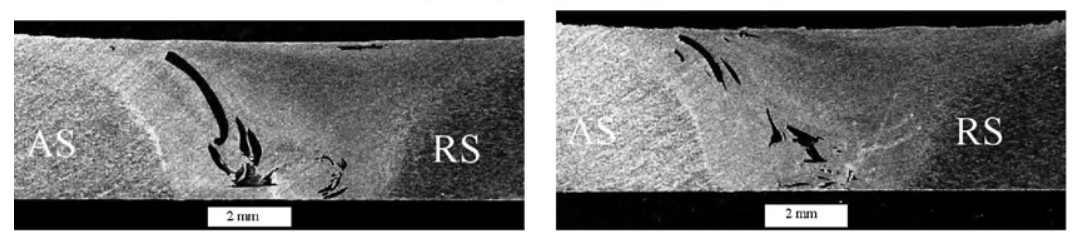

$V=900 \mathrm{~mm} / \mathrm{min}, \mathrm{F}=1200 \mathrm{~kg}, \omega=900 \mathrm{rpm}$
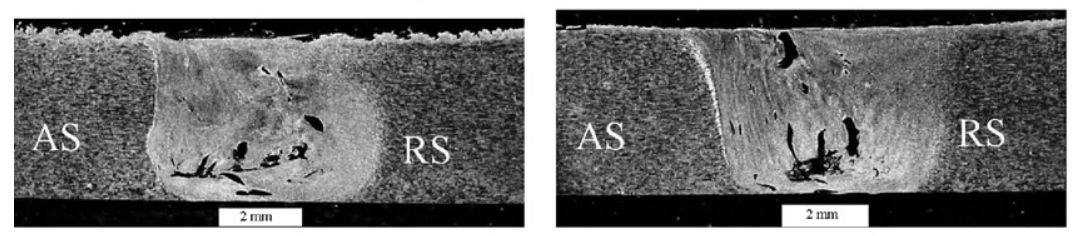

$\mathrm{V}=900 \mathrm{~mm} / \mathrm{min}, \mathrm{F}=750 \mathrm{~kg}, \omega=1620 \mathrm{rpm}$

Fig. 6. Macro-sections of the weld joint for various process parameters $(V, F, \omega)$ and for the two pins and an initially longitudinal copper foil.

Here again, we found that GP and LP increase and then decrease when increasing $F \omega$. These results suggest that the frictional heat is mainly responsible for the thickness of the zone affected by the shoulder. As the frictional heat increases, the heat transfer produces a temperature increase along with the thickness. The rotation of the shoulder on the top surface causes the temperature, near the shoulder/plate interface, to be higher than the temperature near the bottom surface. So the material near the top surface becomes soften and easier to be stirred. This result is confirmed by numerical simulations performed by Zhang and Zhang (2008, 2009b) who simulated a welding thin plate of $3 \mathrm{~mm}$, so in similar conditions to those of this current experimental work. They found that the temperature is higher and more uniform with increasing the rotation speed and/or the external work applied on the numerical FSW system. Thus, the shoulder dominated zone extends over the plate thickness when $F \omega$ increases. The subsequent decrease of $L_{2}, L_{3}, G P$ and LP with $F \omega$ is not completely understood. Two reasons can be suggested:

(1) the friction coefficient can vary with temperature, relative velocity and the plunge force (Elangovan and Balasubramanian, 2007; Nandan et al., 2008). As the workpiece is heated, localized 
softening and/or local melt reduce friction and the heat generation rate. As a result, the fraction of the mechanical power $F \omega$ which is converted to heat can decrease leading to a thinner shoulder dominated zone;

(2) a localisation phenomenon can occur during the process. The higher $F \omega$ increases the heating which results in a material softening. As suggested by Colegrove and Shercliff (2006), this localizes the deformation and reduces the deformation region size.

Note also that, irrespective of the pin geometry, $L_{3}$, GP and LP, associated with the highest value of $F \omega$ (and to the highest rotational speed) are much smaller than the measured data corresponding to the other cases. Actually, for the experiments at $\omega=1620 \mathrm{rpm}$, the plunge force was taken quite low $(750 \mathrm{~kg})$ with regard to the high rotational speed and other plunge force values (Table 1). As a result, the shoulder does not probably make firm contact with the top surface. Thus, the momentum transport from the rotating shoulder is not high enough to drive the material flow as illustrated on the cross-sections presented in Fig. 6. This result illustrates the key role of the plunge force on the weld joint. To sum up, the impact of the shoulder results from two effects: a thermal effect relating to the frictional heating and a mechanical effect related to the capacity of the shoulder to drive the flow. Note that the shoulder prevents also the material from escaping from the work-piece (Nandan et al., 2008).

Interestingly, GP and LP are higher for the SC pin than for the TC3F pin. In addition, the difference between GP and LP is greater for the SC pin than for the TC3F pin. In other words, the joint profile evolves more abruptly along with the plate thickness when using the tapered cylindrical pin with three flats. These two results indicate that the upper shoulder dominated zone is thinner when using the TC3F pin than when using the SC pin.

\subsection{Tracer studies: analysis of the material flow path using thin foil of copper as tracers}

\subsubsection{Results in longitudinal direction}

Fig. 6 exhibits typical weld macro-sections. Similar results (concerning the shape of the weld discussed in Section 3.1 as well as the defects) to the ones obtained without the thin sheet of copper were found. Consequently, we consider that the presence of a thin sheet of copper does not modify the material flow during the process. Clearly we observe that the thin sheet of copper is cut in several pieces along the thickness. In addition, though the copper sheet is initially placed in weld centreline, some pieces are found in both side of the joint line. In the upper portion of the weld, we observe that the copper pieces are in the AS quite far from the weld centreline whereas they are in the RS in the lower portion and closer from the centreline. It is worth noticing than the thin sheet of copper follows the shape of the weld at the AS. Fratini et al. (2006) found similar observations for very equivalent friction stir welding conditions conducted in a $3 \mathrm{~mm}$ thick aluminium alloy plate using a straight cylindrical pin.

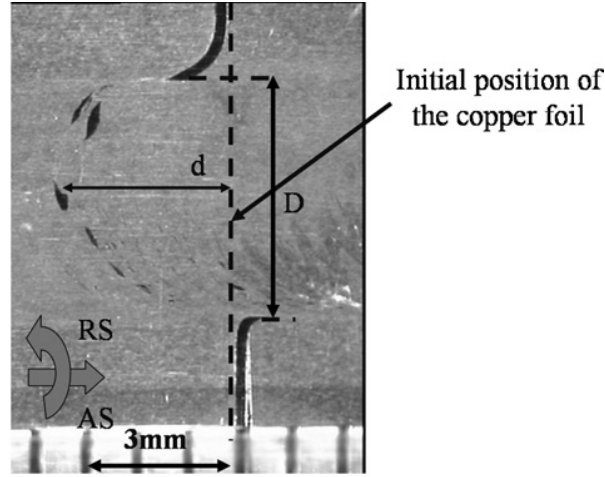

(a) (b)

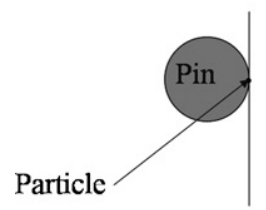

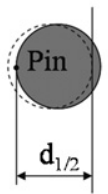

(c)

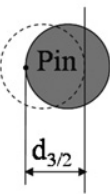

(d)
Fig. 7. Macro-section parallel to the plan section of the weld joint, at the weld root with a transverse copper foil: (a) experimental observation, (b) initial position of particle, (c) position after a half a revolution and (d) position after a revolution and a half.

\subsubsection{Results in transverse direction}

Visualisation of material movement was observed by inserting a copper foil into the workpiece transverse to the welding direction. Plan views at two depths were analysed: in the upper portion of the weld just underneath the shoulder and in the lower part of the weld at $3.9 \mathrm{~mm}$ from the plate surface (Fig. 2b). Fig. 7a shows a typical macro-section at the bottom of the pin. We observe that the copper foil is cut in small pieces which are behind the tool and more or less far from the initial foil position along the joint line. Guerra et al. (2003) estimated the nominal strain related to the motion and the rotation of the pin that a copper foil would sustain. The nominal strain was found of the order of $10,000 \%$. The foil is unable to sustain such very large elongations and tears apart into the small elongated particles as illustrated in Fig. 7a. A part of foil initially on the AS is carried forward with the motion of the tool. At the RS of the weld, the foil is observed backward relative to the tool motion. This behavior is consistent with that observed in other experimental studies (Guerra et al., 2003; Liechty and Webb, 2007; Reynolds et al., 1999) and numerical simulations (Xu and Deng, 2003). The distance, $D$ (Fig. 7a), between the two pieces of the copper foil that are unbroken corresponds more or less to (1) the diameter of the shoulder for plan sections of the upper part of the weld and (2) the diameter of the pin for plan sections at the bottom of the weld.

Table 2 gives three characteristic lengths determined from plan views (Fig. 7b) at the weld root. Maximal position, $d$, denotes the highest measured distance between the initial position of the copper foil and the maximal position of a copper piece found behind the tool (Fig. 7a). $d_{1 / 2}$ is the hypothetic distance of a particle esti-

Table 2

Characteristic lengths for the joint obtained with various process parameters $(V, F, \omega)$ deduced from observations of the weld root with transverse copper foil.

\begin{tabular}{|c|c|c|c|c|c|c|c|c|c|}
\hline \multirow[t]{2}{*}{$V(\mathrm{~mm} / \mathrm{min})$} & \multirow[t]{2}{*}{$F(\mathrm{~kg})$} & \multirow[t]{2}{*}{$\omega(\mathrm{rpm})$} & \multirow[t]{2}{*}{$V / \omega(\mathrm{mm} /$ turn $)$} & \multicolumn{3}{|l|}{ SC } & \multicolumn{3}{|l|}{ TC3F } \\
\hline & & & & $\begin{array}{l}\text { Maximal } \\
\text { position } d(\mathrm{~mm})\end{array}$ & $\begin{array}{l}d_{1 / 2} \\
(\mathrm{~mm})\end{array}$ & $\begin{array}{l}\text { Tool marks } \\
\text { distance }(\mathrm{mm})\end{array}$ & $\begin{array}{l}\text { Maximal } \\
\text { position }(\mathrm{mm})\end{array}$ & $\begin{array}{l}d_{1 / 2} \\
(\mathrm{~mm})\end{array}$ & $\begin{array}{l}\text { Tool marks } \\
\text { distance }(\mathrm{mm})\end{array}$ \\
\hline 100 & 750 & 300 & 0.33 & 2.5 & 4.83 & 0.3 & 4 & 4.83 & 0.3 \\
\hline 100 & 600 & 600 & 0.17 & 3.5 & 4.92 & 0.15 & 4 & 4.92 & 0.15 \\
\hline 500 & 900 & 900 & 0.56 & 3.5 & 4.72 & 0.5 & 3.5 & 4.72 & 0.5 \\
\hline 900 & 1200 & 900 & 1.00 & 3.5 & 4.5 & 1.0 & n.a. & 4.5 & 1.0 \\
\hline 900 & 750 & 1620 & 0.56 & 3.5 & 4.72 & 0.5 & 4 & 4.72 & 0.5 \\
\hline
\end{tabular}


mated by the following procedure. Let us assume that a particle of the copper foil in the weld centreline initially in contact with the pin remains in contact with the pin during the rotation. In other words, we assume no sliding between the pin and the material point. This hypothesis is suggested by the velocity field found by Colegrove and Shercliff (2006) and material flow analysis of material points at advancing side presented by Zhang et al. (2007) from two-dimensional numerical simulations. This hypothesis is justified by literature results which concluded to the presence of a rotating layer around the pin (Ouyang and Kovacevic, 2002; Guerra et al., 2003; Schmidt et al., 2006; Nandan et al., 2007). Let us assume also that vertical motion does not occur and that most material marker stay at the depth at which is started. This hypothesis is justified by Colligan's works (1999) which showed very low vertical motion at the bottom of the weld. If the particle rotates just a half of one turn, then we should find it at a position $d_{1 / 2}$ (Fig. 7c):

$d_{1 / 2}=D_{\mathrm{p}}-\frac{1}{2}\left(\frac{V}{\omega}\right)$

where $D_{\mathrm{p}}$ is the pin diameter.

The third length is the distance between two tool marks mesured at the weld root. Note that these tool marks were observed either under the shoulder or at the weld root. Concerning this third lenght, it was found constant for a given joint and equal to the pitch. These results is commonly found in literature (Colligan, 1999; Krishnan, 2002; Gratecap, 2007; Cui et al., 2008; Xu and Deng, 2008). The tool marks are often attributed to the threads of pins. The lack of such threads in our experiments demonstrates that other reasons must be considered. For example, Gratecap (2007) claims that the tool marks are due to a defect of coaxiality between the symmetry axis and the rotation axis of the tool. From numerical simulations, Zhang and Zhang (2008) correlated the rings' texture to the equivalent plastic strain distributions. Further experiements are required to better understand the origin of these marks.

The maximal position is found nearly constant, irrespective to the welding parameters but is larger in the case of the TC3F pin than on the case of the SC pin. This result is attributed to the higher radius of action of the TC3F pin with respect to the SC pin. Indeed, the presence of flats create a natural eccentricity which increases the volume of interest of the stirring action (Thomas and Nicholas, 1997; Elangovan and Balasubramanian, 2007, 2008). Using a two-dimensional model, Colegrove and Shercliff (2006) showed that there is a greater amount of material being deformed at a higher strain rate with a triflat (TC3F) pin than a cylindrical (SC) tool for the same rotation speed. Accordingly, the TC3F pin has a more significant effect on the flow than the SC tool. As a result, the radial movement of the marker is larger. Fratini et al. (2006) related such an effect comparing the stirring action between cylindrical and tapered pins. Moreover the distance is smaller than $d_{1 / 2}$. This result means that either the particles traveled several times around the rotating pin as confirmed by other literature experiments (Ouyang and Kovacevic, 2002; Guerra et al., 2003; Schmidt et al., 2006; Nandan et al., 2007) and two-dimensional numerical studies (Zhang et al., 2005; Colegrove and Shercliff, 2006) or there is a sliding between the particles and the pin as suggested by the three-dimensional numerical results presented by Zhang et al. (2007). Note that both phenomena can occur.

\section{Discussion}

It is commonly admitted that two effects are responsible for the material flow in the FSW process. First is the extrusion process. The plunge force and the motion of the tool pin propel the material behind the tool. The second is due to the rotation of the tool which stirs the material. Several experimental and numerical flow studies demonstrate the presence of a rotational zone (also called rotating layer) near the pin where the material travels several times around the rotating pin, as indicated by previous studies (Ouyang and Kovacevic, 2002; Guerra et al., 2003; Colegrove and Shercliff, 2006; Schmidt et al., 2006; Nandan et al., 2007; Zhang and Zhang, 2008). The shape and the size on this rotating layer depend on the material properties, the welding parameters and the geometry of the tool (see e.g. Nandan et al., 2007). The rotating layer is larger when it is closer to the shoulder due to greater momentum transport from the rotating shoulder (Nandan et al., 2007). Clearly, the shape of the weld joint revealed on macrographs can be correlated with the size of the rotating layer at each vertical depth (Zhang and Zhang, 2009b). In this work, we found that the size of the weld joint located between the shoulder dominated zone and the pin dominated zone increased and then decreased with increasing the product of the plunge force and the rotational speed $F \omega$. F $\omega$ can be associated with the heat generated by friction between the shoulder and the work-piece. Consequently and following Colegrove and Shercliff (2006), the reduction of the deformation size with increasing $F \omega$ is attributed to a material softening and localization phenomena. Besides, the profile of the weld along the plate thickness is more abrupt when using the TC3F pin than the SC pin. The three flat faces change the material flow generated by the shoulder and create more variation of the material velocity than the SC tool. Elangovan and Balasubramanian $(2007,2008)$ mentioned that pin profiles with flat faces produce a pulsating action which perturbs the material flow. For instance, the TC3F pin produces 30 pulses $/ \mathrm{s}$ when the tool rotates at a speed of $60 \mathrm{rpm}$. There is no pulsating action in the case of straight cylindrical pin. The pulse action is expected to increase the strain rate for a greater amount of material (Colegrove and Shercliff, 2006). The higher strain rate for a greater amount of material increases the temperature which results in a material softening. This localizes the deformation and reduces the deformation region size. This scheme explains why the deformation size is found smaller for the TC3F pin than for the SC pin.

Around the rotating layer, there exists a shear zone, also called transition zone (Schmidt et al., 2006). The shear zone is of finite thickness and separates the parent material from the rotating layer. As mentioned above, the largest portion of the rotating layer but also the shear zone (Sanders, 2007) is near the shoulder and the smallest at the bottom of the plates. The part of the copper foil (placed between the adjoining plates) positioned close to the bottom of the plates is very slightly subjected to the rotating layer. Consequently, and as suggested by Sanders (2007), it stays within the shear zone and copper pieces are deposited along the weld joint axis as illustrated in Fig. 6. On the opposite, the part of the copper foil positioned close to the shoulder has a better chance of being subjected to a larger portion of the rotating layer and of travelling several times around the pin before to be pushed out the deformation zone. As a result, pieces of copper foil are expected farer from the weld joint axis, as shown in Fig. 6. In addition, they are deposited at the advancing side due to the tool action moving the material from the retreating side towards the advancing side on the back side of the tool (Fratini et al., 2006). It should be observed that in the bottom part of the joint, "wormhole" defects systematically formed revealing an inadequate material flow, whatever the pitch value and the tool geometry. This observation could indicate the presence of a too low vertical motion towards the bottom of the weld (Elangovan and Balasubramanian, 2007; Nandan et al., 2008; Lee et al., 2008). The absence of vertical striations seems to confirm the lack of effective vertical flow (Nandan et al., 2008; Krishnan, 2002), commonly attributed to threading on the tool pin (Guerra et al., 2003; Nandan et al., 2008). Further investigations using copper wire are required to assess that a vertical component of the motion occurs in the friction stir welding conditions studied here. 


\section{Conclusions}

Experimental observations have been proposed for two different tool shapes with unthreaded pin and for several welding parameters combinations. We showed that the material flow with unthreaded tool has the same features as the material flow using classical threaded tools: material is deposited in the AS in the upper part of the weld and in the RS in the lower part of the weld; a rotating layer appears around the tool. Macro-sections of the joints demonstrated that the zone influenced by the shoulder rotation along the thickness is thicker when increasing the product of the plunge force and the rotational speed and for the cylindrical pin than for the tapered pin with three flats. The three flat faces change the material flow generated by the shoulder and create more variation of the material velocity than the straight cylindrical pin. Tool marks pattern in plane parallel to sheet surface of spacing equal to pitch was observed despite the use of unthreaded pins.

\section{Aknowledgements}

The authors wish to acknowledge Institut de Soudure for financial and experimental support and Conseil Régional de Lorraine for financial support for this work. It was performed within the framework of the FSLOR project.

\section{References}

Bastier, A., Maitournam, M.H., Roger, F., Dang Van, K., 2008. Modelling of the residual state of friction stir welded plates. Journal of Materials Processing Technology 200, 25-37.

Colligan, K., 1999. Material flow behaviour during friction stir welding of aluminum. Welding Journal 78, 229-237.

Cui, G.R., Ma, Z.Y., Li, S.X., 2008. Periodical plastic flow pattern in friction stir processed Al-Mg alloy. Scripta Materialia 58, 1082-1085.

Colegrove, P., Shercliff, H.R., 2006. CFD modelling of friction stir welding of thick plate 7449 aluminium alloy. Science and Technology of Welding and Joining 11 , 429-441.

Dickerson, T., Shercliff, H.R., Schmidt, H., 2003. A weld marker technique for flow visualization in friction stir welding. In: Proceedings of the 4th Internationnal Symposium on Friction Stir Welding, Park City, Utah, USA.

Elangovan, K., Balasubramanian, V., 2007. Influence of pin profile and rotational speed of the tool on the formation of friction stir processing zone in AA2219 aluminium alloy. Materials Science and Engineering: A 459, 7-18.

Elangovan, K., Balasubramanian, V., 2008. Influences of tool pin profile and tool shoulder diameter on the formation of friction stir processing zone in AA6061 aluminium alloy. Materials and Design 29, 362-373.

Fratini, L., Buffa, G., Palmeri, D., Hua, J., Shivpuri, R., 2006. Material flow in FSW of AA7075-T6 butt joints: continuous dynamic recrystallization phenomena. Journal of Engineering Materials and Technology 128, 428435.

Fourment, L., Guerdoux, S., 2008. 3D numerical simulation of the three stages of friction stir welding based on friction parameters calibration. International Journal of Material Forming 11, 1287-1290.

Gratecap, F., 2007. Contributions au procédé de soudage par frottement et malaxage FSW. PhD thesis, École Centrale de Nantes, France.

Guerra, M., Schmidt, C., McClure, J.C., Murr, L.E., Nunes, A.C., 2003. Flow pattern during friction stir welding. Materials Characterization 49, 95-101.
Krishnan, K.N., 2002. On the formation of onion rings in friction stir welding. Materials Science and Engineering: A 327, 246-251.

Lee, C.Y., Lee, W.B., Kim, J.W., Choi, D.H., Yeon, Y.M., Jung, S.B., 2008. Lap joint properties of FSWed dissimilar formed $5052 \mathrm{Al}$ and $6061 \mathrm{Al}$ alloys with different thickness. Journal of Materials Science 43, 3296-3304.

Li, Y., Murr, L.E., McClure, J.C., 1999. Flow visualization and residual microstructures associated to friction-stir welding of 2024 aluminum to 6061 aluminum. Materials Science and Engineering: A 271, 213-223.

Liechty, B.C., Webb, B.W., 2007. The use of plasticine as an analog to explore material flow in friction stir welding. Journal of Materials Processing Technology 184, 240-250.

Mishra, R.S., Ma, Z.Y., 2005. Friction stir welding and processing. Materials Science and Engineering 50,1-78.

Nandan, R., Roy, G.G., Lienert, T.J., Debroy, T., 2007. Three dimensional heat and material flow during friction stir welding of mild steel. Acta Materialia 55, 883-895.

Nandan, R., Debroy, T., Bhadeshia, H.K.D.H., 2008. Recent advances in friction-stir welding-Process, weldment structure and properties. Progress in Materials Science 53, 980-1023.

Ouyang, J., Kovacevic, R., 2002. Material flow and microstructure in the friction stir butt welds of the same and dissimilar aluminum alloys. Journal of Materials Engineering and Performance 11, 51-63.

Prado, R.A., Murr, L.E., Shindo, D.J., Soto, K.F., 2001. Tool wear in friction-stir welding of aluminium alloy $6061+20 \% \mathrm{Al}_{2} \mathrm{O}_{3}$ : a prelimenary study. Scripta Materialia $45,75-80$.

Prado, R.A., Murr, L.E., Soto, K.F., McClure, J.C., 2003. Self-optimization in tool wear for friction-stir welding of $\mathrm{Al} 6061+20 \% \mathrm{Al}_{2} \mathrm{O}_{3}$ MMC. Materials Science and Engineering: A 349, 156-165.

Reynolds, A.P., Seidel, T.U., Simonsen, M., 1999. Visualization of material flow in an autogenous friction stir weld. In: Proceedings of the 1st Internationnal Symposium on Friction Stir Welding, Thousand Oaks, California, USA.

Sanders, J., 2007. Understanding the material flow path of the friction stir welding process. Master thesis, Faculty of Missipi State University, USA

Schmidt, H.N.B., Dickerson, T.L., Hattel, J.H., 2006. Material flow in butt friction stir welds in AA2024T3. Acta Materialia 54, 1199-1209.

Schmidt, H., Hattel, J., 2005. A local model for the thermomechanical conditions in friction stir welding. Modelling and Simulation in Material Science and Engineering 13, 77-93.

Schneider, J., Beshears, R., Nunes Jr., A.C., 2006. Interfacial sticking and slipping in the friction stir welding process. Materials Science and Engineering: A 435-436, 297-304.

Seydel, T.U., Reynolds, A.P., 2001. Visualization of material flow in AA2195 friction-stir welds using a marker insert technique. Metallurgical and Materials Transactions A 32, 2879-2884.

Thomas, W.M., Nicholas, E.D., 1997. Friction stir welding for the transportation industries. Materials and Design 18, 269-273.

Xu, S., Deng, X., 2003. Two-Dimensional Finite Element Simulation of Material Flow in the Friction Stir Welding Process. Journal of Manufacturing Processes 2, 125-133.

Xu, S., Deng, X., 2008. A study of texture patterns in friction stir welds. Acta Materialia $56,1326-1341$.

Zhao, Y.H., Lin, S.B., Wu, L., Qu, F.X., 2005. The influence of pin geometry on bonding and mechanical properties in friction stir weld $2014 \mathrm{Al}$ alloy. Materials Letters $59,2948-2952$.

Zhang, H.W., Zhang, Z., Chen, J.T., 2005. The finite element simulation of the friction stir welding process. Materials Science and Engineering: A 403, 340-348.

Zhang, H.W., Zhang, Z., Chen, J.T., 2007. 3D modeling of material flow in friction stir welding under different process parameters. Journal of Materials Processing Technology 183, 62-70.

Zhang, Z., Zhang, H.W., 2008. A fully coupled thermo-mechanical model of friction stir welding. International Journal of Advanced Manufacturing Technology 37 279-293.

Zhang, Z., Zhang, H.W., 2009a. Numerical studies on the effect of transverse speed in friction stir welding. Materials and Design 30, 900-907.

Zhang, Z., Zhang, H.W., 2009b. Numerical studies on controlling of process parameters in friction stir welding. Journal of Materials Processing Technology 209, 241-270. 